\title{
Zinc and magnesium in bull and boar spermatozoa
}

\author{
S. Arver and R. Eliasson \\ Reproductive Physiology Unit, Faculty of Medicine, Karolinska Institutet, S-104 01 Stockholm, \\ Sweden
}

\begin{abstract}
Summary. Mean \pm s.e.m. concentrations ( $\mathrm{nmol} / 10^{8}$ cells) of zinc and magnesium in bull spermatozoa were $30.6 \pm 6.6$ and $119 \pm 28 \cdot 8$, respectively. Corresponding values for boar spermatozoa were $16.9 \pm 1.98$ and $57.1 \pm 4 \cdot 3$. Bull spermatozoa washed twice in a standard buffered salt solution, $\mathrm{pH} 7.75$, lost $72.6 \%$ of their zinc and $46.5 \%$ of their magnesium. Boar spermatozoa lost $40 \%$ of $\mathrm{Zn}$ and $18 \%$ of $\mathrm{Mg}$, respectively. Addition of albumin (4\% final concentration) to the washing solution did not increase the loss of ions from bull spermatozoa but increased the loss of zinc and magnesium from boar spermatozoa to $52 \%$ and $41 \%$, respectively.
\end{abstract}

\section{Introduction}

In most mammals the seminal plasma and spermatozoa have a high content of zinc and magnesium (for references see Bertrand \& Vladesco, 1921; Lindholmer \& Eliasson, 1972). The biochemical or physiological significance of these ions for sperm function is little understood although zinc is believed to be important for membrane and chromatin stability and possibly also for the mechanical properties of the accessory fibres, the tail morphology, and sperm motility (Blom \& Wolstrup, 1976; Baccetti, Pallini \& Burrini, 1976; Eliasson \& Kvist, 1976; Johnsen \& Eliasson, 1978a; Kvist \& Eliasson, 1978). In human semen a high sperm zinc content is often associated with poor motility (Lindholmer \& Eliasson, 1974).

Human spermatozoa lose zinc and magnesium when they are washed with salt solutions containing zinc binding agents, e.g. albumin or histidine (Lindholmer \& Eliasson, 1972; Huacuja, Sosa, Delgado \& Rosado, 1973; Johnsen \& Eliasson, 1978b). Removal of zinc from the spermatozoa results in increased oxygen consumption after addition of succinate (Eliasson, Johnsen \& Lindholmer, 1971; Huacuja et al., 1973) and increased formation of lipid peroxides (Johnsen \& Eliasson, 1978a). The uptake or release of zinc by spermatozoa varies with species (Birnbaum, Hall \& Lee, 1961; Lindholmer \& Eliasson, 1974). Boar spermatozoa take up considerable amounts of zinc from the seminal plasma if they are damaged, probably as a result of a disturbed membrane function (Westmoreland, First \& Hoekstra, 1967).

It has been proposed that the zinc content of spermatozoa is of importance for their fertilizing ability (Gunn \& Gould, 1958; Johnsen \& Eliasson, 1976, 1978a). To improve understanding of the physiological significance of zinc and magnesium in boar and bull spermatozoa comparative studies have been planned. One part of the programme is to investigate the sperm content of these ions after different treatments.

\section{Material and Methods}

Semen samples were obtained from animals kept at the Department of Obstetrics \& Gynecology, College of Veterinary Medicine, Swedish University of Agricultural Sciences, 
Uppsala. Semen was collected with an artificial vagina and only samples with normal qualities in the routine analysis were used. Boar semen was immediately filtered on a nylon sieve to remove the gel. The samples were transported under temperature-controlled conditions.

Six bulls and 6 boars provided one semen sample each. Each sample was divided into 3 aliquots. One was used as a control and the 2 others were centrifuged for $20 \mathrm{~min}$ at $400 \mathrm{~g}$. The supernatant was discarded and the pellet was suspended in twice the original volume with a buffered salt solution with (BSSA) or without (BSS) albumin. The composition of BSS was the following (mM): $\mathrm{NaCl} 123, \mathrm{KCl} 5, \mathrm{HCl} 2 \cdot 4$, Tris $3 \cdot 7 ; \mathrm{pH} 7 \cdot 75$ ). When human serum albumin was used the final concentration was $4 \%(\mathrm{v} / \mathrm{w})$. The centrifugation procedure was repeated once but the added volume of BSS or BSSA corresponded to the original semen volume. The spermatozoa were then separated from the seminal plasma or the suspending medium by centrifugation through a discontinuous Ficoll 400 gradient (Pharmacia, Uppsala, Sweden) as described by Lindholmer \& Eliasson (1972). The densities of the Ficoll layers were, however, adjusted to specific gravities of $1.0600,1.0934$ and 1.1432 for separation of bull spermatozoa and 1.0600 , 1.0934 and 1.1600 , for separation of boar spermatozoa. The buoyant density of bull spermatozoa is just below 1.1432 (Benedict, Schumaker \& Davies, 1967). The spermatozoa were recovered from the lower part of the second layer and resuspended in a saponin-sodium hydroxide solution (535 $\mathrm{g}$ saponin in $1000 \mathrm{ml} 1 \mathrm{mM}-\mathrm{NaOH}$ ) and an aliquot was taken for determination of sperm concentration. The remaining part was mixed with one volume of $4 \mathrm{M}-\mathrm{NaOH}$ and placed in a water bath $\left(70^{\circ} \mathrm{C}\right.$ for $\left.1 \mathrm{~h}\right)$. Zinc and magnesium were then assayed by an atomic absorption technique (Lindholmer \& Eliasson, 1972). When seminal plasma was assayed it was first diluted 1:50 with distilled water.

Values are given as mean and s.e.m. and statistical significance of differences was tested with Student's $t$-test for paired analyses.

\section{Results}

The measurements for zinc and magnesium in bull and boar spermatozoa and seminal plasma are shown in Table 1 . The coefficent of variation between quadruplicates was $10 \%$. When bull spermatozoa were washed they lost both zinc and magnesium (Text-fig. 1a). The mean loss was $72.6 \%$ (range $64-95 \%$ ) for zinc and $46.5 \%$ (range $21-71 \%$ ) for magnesium. There was no difference between the two buffers. The washing procedures also decreased the zinc and magnesium content of boar spermatozoa (Text-fig. 1b), but the loss was only $18 \%(\mathrm{Mg})$ and $40 \%(\mathrm{Zn})$ in BSS. Addition of albumin to the washing medium (BSSA) increased the loss to $41 \%$ $(\mathrm{Mg})$ and to $59 \%(\mathrm{Zn})$.

Table 1. Values for zinc and magnesium in spermatozoa and seminal plasma from bull and boar

\begin{tabular}{|c|c|c|c|c|}
\hline & \multicolumn{2}{|c|}{ Bull } & \multicolumn{2}{|c|}{ Boar } \\
\hline & $\begin{array}{l}\text { Spermatozoa } \\
\left(\mathrm{nmol} / 10^{8} \text { cells }\right)\end{array}$ & $\begin{array}{c}\text { Seminal } \\
\text { plasma } \\
\text { (mM) }\end{array}$ & $\begin{array}{c}\text { Spermatozoa } \\
\left(\mathrm{nmol} / 10^{8} \text { cells }\right)\end{array}$ & $\begin{array}{c}\text { Seminal } \\
\text { plasma } \\
\text { (mM) }\end{array}$ \\
\hline Zinc & $\begin{array}{r}30 \cdot 6 \pm 6 \cdot 6 \\
(18 \cdot 4-62 \cdot 4)\end{array}$ & $0.4 \pm 0.05$ & $\begin{array}{l}16.9 \pm 1.98 \\
(11 \cdot 3-25 \cdot 1)\end{array}$ & $0.7 \pm 0.03$ \\
\hline $\mathrm{Mg}$ & $\begin{array}{l}119.6 \pm 28.8 \\
(54.3-252.8)\end{array}$ & $2 \cdot 7 \pm 0 \cdot 14$ & $\begin{array}{l}57 \cdot 1 \pm 4 \cdot 3 \\
(41 \cdot 5-64 \cdot 9)\end{array}$ & $3.2 \pm 0.05$ \\
\hline
\end{tabular}




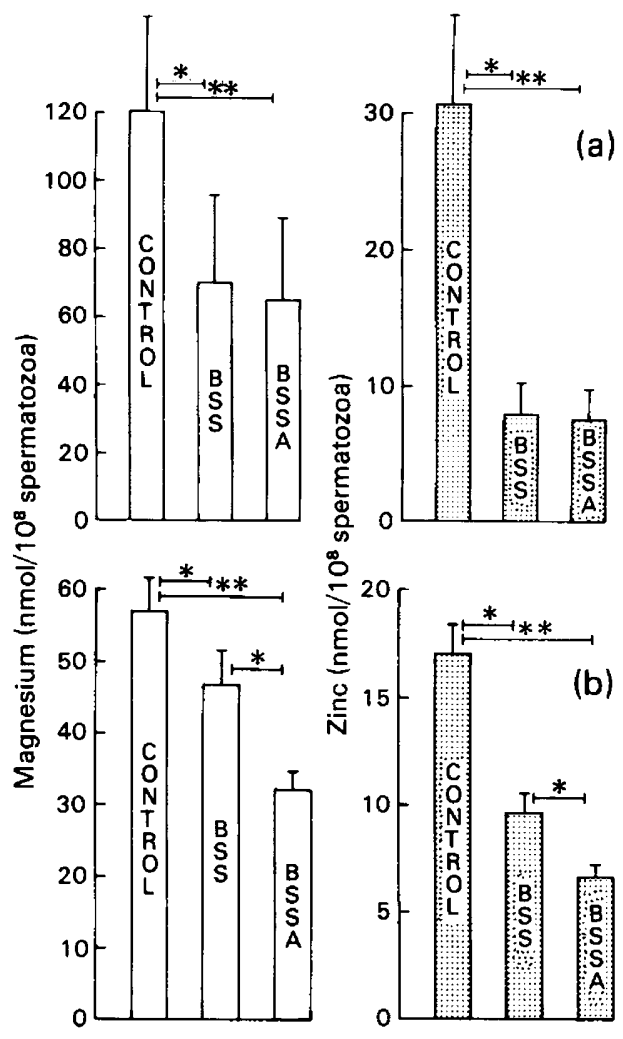

Text-fig. 1. Magnesium and zinc contents in (a) bull and (b) boar spermatozoa before and after washing with buffered salt solution without (BSS) and with (BSSA) albumin. Values are mean \pm s.e.m. for 6 samples and significant differences are indicated: ${ }^{*} P<0.025 ;{ }^{* *} P<0.01$.

\section{Discussion}

The zinc and magnesium contents of bull and boar semen differ from those measured for human spermatozoa ( 84 and $92 \mathrm{nmol} / 10^{8}$ cells) and seminal plasma (1-5 and 2-9 mM, respectively) (Lindholmer \& Eliasson, 1972; Eliasson, 1975). The possible physiological significance of these differences is at present not understood.

Bull and boar spermatozoa lost zinc and magnesium when washed with either buffer. Bull spermatozoa lost about the same proportion of the two ions in BSS or BSSA. Since a mild chelating agent like albumin did not remove more zinc and magnesium than was exchanged by diffusion, it seems that the ions are loosely bound. Boar spermatozoa lost significantly more of the two ions when the washing fluid contained albumin. Under similar conditions Johnsen \& Eliasson (1978b) found that human spermatozoa lost insignificant amounts of zinc in BSS and about $70-80 \%$ of the zinc in BSSA.

Albumin and follicular fluid have been reported to induce capacitation of spermatozoa (Barros \& Austin, 1967; Yanagimachi, 1969) and the active factor in bovine follicular: fluid has been shown to be albumin (Lui, Cornett \& Meizel, 1977). Spermatozoa will lose zinc during their transit through the female genital tract (Gunn \& Gould, 1958) and removal of zinc from the spermatozoa can be closely associated with capacitation and fertilization as recently proposed by Johnsen \& Eliasson $(1976,1978 \mathrm{a})$. The importance of zinc for $_{\text {capacitation has }}$ 
also been emphasized by Aonuoma, Okabe \& Kawaguchi (1978). It thus seems of importance to consider the effect of a washing procedure on the physiological properties of the spermatozoa.

We thank Professor S. Einarsson and Dr K. Larsson for their help in providing bull and boar semen. Financial support was received from the Karolinska Institutets Fonder.

\section{References}

Aonuoma, S., Okabe, M. \& Kawaguchi, M. (1978) The effect of zinc ions on fertilization of mouse ova in vitro. J. Reprod. Fert. 53, 179-183.

Baccetti, B., Pallini, V. \& Burrini, A.G. (1976) The accessory fibers of the sperm tail. II. Their role in binding zinc in mammals and Cephalopods. $J$. Ultrastruct. Res. 54, 261-275.

Barros, C. \& Austin, C.R. (1967) In vitro fertilization and sperm acrosome reaction in hamster. $J$. exp. Zool. 166, 317-324.

Benedict, R.C., Schumaker, V.N. \& Davies, R.E. (1967) The buoyant density of bovine and rabbit spermatozoa. J. Reprod. Fert. 13, 237-249.

Bertrand, G. \& Vladesco, R. (1921) Intervention probable du zinc dans les phénomènes de fécondation chez les animaux vertébrés. $C$. r. hebd. Séanc. Acad. Sci., Paris D 173, 176-179.

Birnbaum, D., Hall, T. \& Lee, R. (1961) The zinc content of rat sperm cells from ejaculate, vas, epididymis and testis. Proc. Soc. exp. Biol. Med. 108, 321-324.

Blom, E. \& Wolstrup, C. (1976) Zinc as a possible causal factor in the sterilizing sperm tail defect, the "Dag defect" in Jersey bulls. Nord. VetMed. 28, 515-518.

Eliasson, R. (1975) Analysis of semen. In Progress in Infertility, Vol. II, pp. 691-713. Eds J. Behrman \& R. W. Kistner. Little, Brown \& Co, Boston.

Eliasson, R. \& Kvist, U. (1976) Importance of seminal plasma components on the structural stability of human spermatozoa. Andrologia 8, Suppl. 1, 119120. Abstr.

Eliasson, R., Johnsen, Ø. \& Lindholmer, C. (1971) Effect of zinc on human sperm respiration. Life Sciences 10, 1317-1320.

Gunn, S.A. \& Gould, Th.C. (1958) Role of zinc in the fertility and fecundity in the rat. $J$. Physiol., Lond. 193, 505-508.

Huacuja, L., Sosa, A., Delgado, N.M. \& Rosado, A. (1973) A kinetic study of the participation of zinc in human spermatozoa metabolism. Life Sciences 13, 1383-1394.

Johnsen, Ø. Eliasson, R. (1976) Follicular fluid and succinate oxidation by human spermatozoa. Andrologia 8, 283-284.

Johnsen, Ø. \& Eliasson, R. (1978a) Destabilization of human sperm membranes by albumin, EDTA and histidine. Int. J. Androl. 1, 485-488.

Johnsen, Ø. \& Eliasson, R. (1978b) Studies on the succinate induced respiration of human spermatozoa in relation to zinc ions. Int. J. Androl., Suppl. 1, 175, Abstr.

Kvist, U. \& Eliasson, R. (1978) Zinc dependent chromatin stability in human ejaculated spermatozoa. Int. J. Androl., Suppl. 1, 178. Abstr.

Lindholmer, C. \& Eliasson R. (1972) Zinc and magnesium in human spermatozoa. Int. J. Fertil. 17, 153-160.

Lindholmer, C. \& Eliasson, R. (1974) In vitro release and uptake of zinc and magnesium by human spermatozoa. Int. J. Fertil. 19, 56-62.

Lui, C.W., Cornett, L.E. \& Meizel, S. (1977) Identification of the bovine follicular fluid protein involved in the in vitro induction of the hamster sperm acrosome reaction. Biol. Reprod. 17, 34-41.

Westmoreland, N., First, N.L. \& Hoekstra, W.R. (1967) In-vitro uptake of zinc by boar spermatozoa. $J$. Reprod. Fert. 13, 223-228.

Yanagimachi, R. (1969) In vitro capacitation of hamster spermatozoa by follicular fluid. J. Reprod. Fert. 18, 275-286. 